\title{
Validation of the BATT score for prehospital risk stratification of traumatic haemorrhagic death: usefulness for tranexamic acid treatment criteria
}

\author{
Francois-Xavier Ageron ${ }^{1,2^{*}}$ (D) Timothy J. Coats ${ }^{3}$, Vincent Darioli ${ }^{2}$ and lan Roberts ${ }^{1}$
}

\begin{abstract}
Background: Tranexamic acid reduces surgical blood loss and reduces deaths from bleeding in trauma patients. Tranexamic acid must be given urgently, preferably by paramedics at the scene of the injury or in the ambulance. We developed a simple score (Bleeding Audit Triage Trauma score) to predict death from bleeding.

Methods: We conducted an external validation of the BATT score using data from the UK Trauma Audit Research Network (TARN) from 1st January 2017 to 31st December 2018. We evaluated the impact of tranexamic acid treatment thresholds in trauma patients.

Results: We included 104,862 trauma patients with an injury severity score of 9 or above. Tranexamic acid was administered to 9915 (9\%) patients. Of these 5185 (52\%) received prehospital tranexamic acid. The BATT score had good accuracy (Brier score $=6 \%$ ) and good discrimination (C-statistic 0.90; 95\% Cl 0.89-0.91). Calibration in the large showed no substantial difference between predicted and observed death due to bleeding $(1.15 \%$ versus $1.16 \%, P=$ 0.81). Pre-hospital tranexamic acid treatment of trauma patients with a BATT score of 2 or more would avoid 210 bleeding deaths by treating 61,598 patients instead of avoiding 55 deaths by treating 9915 as currently.

Conclusion: The BATT score identifies trauma patient at risk of significant haemorrhage. A score of 2 or more would be an appropriate threshold for pre-hospital tranexamic acid treatment.
\end{abstract}

Keywords: Trauma, Tranexamic acid, Bleeding, Score, Prognostic model

\section{Introduction}

Tranexamic acid (TXA) reduces surgical blood loss and reduces deaths from bleeding in trauma patients $[1,2]$. TXA must be given urgently, preferably by paramedics at the scene of the injury or in the ambulance [3]. Many bleeding deaths occur soon after injury and there is a $10 \%$ reduction in treatment effectiveness for every 15

\footnotetext{
* Correspondence: fxageron@gmail.com

${ }^{1}$ Clinical Trials Unit, London School of Hygiene \& Tropical Medicine, London WC1E 7HT, UK

${ }^{2}$ Department of Emergency Medicine, Lausanne University Hospital, University of Lausanne, 1011 Lausanne, Switzerland

Full list of author information is available at the end of the article
}

min treatment delay [4]. Paramedics need clear criteria that can be applied at the scene to guide who to treat. We previously developed a prognostic model to predict death from bleeding and showed that the relative reduction in mortality with TXA does not vary with baseline risk $[5,6]$. Because many deaths are in patients at low and intermediate risk, TXA use should not be restricted to the most severely injured [6]. In this study, we derive a simple score that paramedics can use at the scene to help decide who to treat with TXA. We conduct an external validation of the score and explore different TXA treatment thresholds. 


\section{Method}

We developed a simple score (Bleeding Audit and Triage Trauma Score - BATT) to predict death due to bleeding in trauma patients. We conducted an external validation of this score using data from the UK Trauma Audit Research Network (TARN) from 1st January 2017 to 31st December 2018. Finally, we evaluated the impact of TXA treatment thresholds in trauma patients.

\section{Development of the BATT score}

We previously developed and validated a prognostic model to predict death due to bleeding in trauma patients. The methods are described in detail elsewhere [5]. Briefly, data on bleeding trauma patients from 298 hospitals in 41 countries were used to derive the model. We validated the model using an internal-external cross-validation method based on data from 41 countries to ensure that the results are widely applicable. The final prognostic model included age, systolic blood pressure, Glasgow Coma Scale, heart rate, respiratory rate and mechanism of injury. To develop the BATT score, we assigned points for each predictor that were proportional to the coefficients of the regression equation. We added the criterion high velocity trauma as the intercept of the regression equation corresponding to the inclusion criteria of the trauma registry used for the development of prognostic model. High velocity trauma is routinely assessed at the scene and corresponds to injury from road traffic crash (with intrusion, ejection, death in same passenger compartment, and motor vehicle versus pedestrian or bicyclist), fall from high height $(>3 \mathrm{~m})$, blow or blast [7]. An electronic version of the score is available for computer or smartphone: https://www. evidencio.com/models/show/1393

\section{Validation of the BATT score}

We used data from the Trauma Audit Research Network (TARN) from 1st January 2017 to 31st December 2018 to validate the BATT score for use in England and Wales. The TARN database includes data on patients with an Injury Severity Score (ISS) of nine or more who are admitted to hospital in England and Wales for at least three nights, died in hospital or were transferred to another hospital for specialist care [8]. The exclusion criteria were isolated mild traumatic brain injury with loss of consciousness, superficial scalp injury, patients 65 years or older with femoral neck or single pubic rami fracture, fracture or dislocation of the foot or hand, closed fracture or dislocation of an isolated limb, simple skin laceration with blood loss $<20 \%$.

Because death due to bleeding is not recorded in the TARN database, we used early deaths and early deaths with evidence of haemorrhage as a proxy for death due to bleeding. Causes of trauma deaths depend on time and location of death [9]. Prehospital immediate deaths are likely to be due to traumatic brain injury or cardiovascular injuries [10]. The main causes of in-hospital deaths are exsanguination and brain injury [11]. Two studies, one in North America and one including two large European registries (UK and Germany) showed that deaths due to exsanguination occurred within $24 \mathrm{~h}$ with a peak at $6 \mathrm{~h}$ after admission $[9,12]$. Deaths due to head injuries occurred within $72 \mathrm{~h}$ with a peak at $24 \mathrm{~h}$ after admission. Consequently, we included deaths from all cause within $12 \mathrm{~h}$ of injury (excluding asphyxia, drowning, hanging, or massive destruction of skull or brain) and deaths between 12 to $24 \mathrm{~h}$ with evidence of bleeding (activation of massive transfusion protocol or blood within $6 \mathrm{~h}$ or an abbreviated injury scale (AIS) diagnosis associated with haemorrhage listed in the Supplementary file 1).

We assessed the accuracy, discrimination and calibration of the BATT score. Accuracy was assessed using the Brier score. Because the Brier score depends on the prevalence of the outcome, we also calculated the scaled Brier score to account for the baseline risk of death due to bleeding (Supplementary file 2). The scaled Brier score ranges from 0 to $100 \%$ and indicates the degree of error in prediction [13]. A scaled Brier score of $0 \%$ shows perfect accuracy. Discrimination is the ability of the score to correctly identify patients with the outcome. We estimated the sensitivity, specificity, positive and negative likelihood ratio for each threshold of the BATT score. The likelihood ratio is the likelihood of a positive score in a patient with the outcome compared to the likelihood of a positive score in a patient without the outcome [14]. The positive likelihood ratio is the ratio of sensitivity to 1 -specificity. The negative likelihood ratio is the ratio of 1-sensitivity to specificity. A positive likelihood ratio of 10 or above will result in a large increase in the probability of the outcome. A negative likelihood ratio of 0.1 or less will result in a large decrease in the probability of the outcome. We plotted the Receiving Operating Characteristic (ROC) curve which is the sensitivity (true positives) on 1-specificity (false positives) for different threshold of the BATT score [15]. An ideal score will reach the upper left corner (all true positive with no false positive). We estimated the area under the ROC curve (AUROC) that corresponds to the concordance statistic (C-Statistic) for binary outcome. A Cstatistic of 1.0 shows perfect discrimination ability. Calibration is the agreement between observed and predicted outcomes. We estimated calibration in the large as the difference between the mean predicted and observed probabilities and the ratio of the predicted and observed number of events $(\mathrm{P} / \mathrm{O})$. We also plotted the observed and predicted probabilities of death by decile of the score and with local regression based on LOESS 
algorithm [13]. We estimated the calibration intercept and slope of the calibration plot as a measure of spread between predicted and observed outcome. Ideally, the intercept would be zero indicating that the predictions are neither systematically too low or too high and the slope would be 1 [16]. There were missing value for some predictors but no missing outcome data. To estimate baseline risk for the full dataset, we replaced missing predictors using multiple imputation by chained equations on early death, age, systolic blood pressure, respiratory rate, heart rate, Glasgow coma scale, time for injury, time for prehospital ambulance arrival, and time for hospital admission with 20 imputed datasets.

\section{Evaluation of TXA treatment criteria}

We evaluated two different TXA treatment strategies: (1) prehospital treatment of all trauma patients with an ISS $\geq 9$ at the scene of the injury, (2) hospital treatment of all trauma patients with an ISS $>9$ in the emergency department (ED). We compared each treatment strategy according to different thresholds of the BATT score to assess its clinical usefulness and treatment criteria.

We estimated the impact of TXA treatment for each treatment criteria. Since randomized trials of TXA in trauma patients report no increase in deaths from adverse events, the net impact of TXA was given by the number of deaths due to bleeding avoided by the treatment $[6,17]$. To estimate the number of deaths avoided by TXA, we predicted the baseline risk of death due to bleeding using our previously published prognostic model [5]. To estimate post-treatment probabilities, we applied the treatment effect to these baseline risks taking into account time to treatment [4]. The risk difference was used to estimate the number of deaths avoided. To account for miscalibration of predicted baseline risks, we conducted a sensitivity analysis using observed early deaths with evidence of haemorrhage as baseline risks. The details of both modelling methods and equations are described in the Supplementary file 3. We plotted the cumulative number of death due to bleeding avoided by BATT score threshold in a decision curve analysis as described by Vickers et al. [18] We compared decision curve analysis for each scenario. We estimated the number needed to treat to save one life for each BATT score threshold and each scenario. The registry-based study design predetermines the sample size. All analyses were performed using STATA software (version 16.0; Stata Corp, College Station, TX, USA).

\section{Results}

Table 1 shows the BATT Score. The minimum score is 0 and the maximum score is 27 .

\begin{tabular}{lll} 
Table 1 BATT score & & \\
\hline Age & $\geq 65$ years old & +1 \\
& $\geq 75$ years old & +2 \\
Systolic Blood Pressure & $<60 \mathrm{mmHg}$ & +14 \\
& $\geq 60 \mathrm{and}<100 \mathrm{mmHg}$ & +5 \\
Glasgow Coma Scale & $\leq 8$ & +4 \\
& $>8$ and $\leq 12$ & +3 \\
Respiratory rate & $<10$ or $\geq 30 /$ min & +2 \\
& Alt: Oxygen saturation $<90$ & +2 \\
Heart rate & $>100 /$ min & +1 \\
Penetrating injury & Yes & +2 \\
High velocity trauma & Yes & +2 \\
\hline The score is not suitable for isolated limb trauma or isolated neck femoral
\end{tabular}

fracture in people older than 65 years

\section{External validation - patient's characteristics}

We validated the score in 104,862 trauma patients with an ISS $\geq 9$ who were transported to hospital by ambulance in England and Wales between 2017 and 2018. Their characteristics are summarized in Table 2. The mean age was 62 years and 3189 (3\%) had penetrating injuries. The median time from injury to ambulance arrival was $69 \mathrm{~min}$, IQR $(24-174)$. Mean ISS was $16( \pm 9)$ and $46 \%$ of patients had an ISS $\geq 16$. TXA was administered in 9915 (9\%) patients. Of these 5185 (52\%) received it prehospital. The median time from injury to treatment was $48 \mathrm{~min}$, IQR (35-68) when TXA was given prehospital and $148 \mathrm{~min}$, IQR (103-251) when it was given in hospital. 2760 (3\%) of the trauma patients received TXA within $1 \mathrm{~h}$ and 5727 (6\%) received TXA within $3 \mathrm{~h}$ of injury. The mean ISS of patients treated with TXA was $23( \pm 13)$ compared with $14( \pm 7)$ for patients who were not treated $(P<0.001)$. Most patients treated with TXA had a low or intermediate risk of death due to bleeding (Fig. 1). Most patients treated had a BATT score of 2 . The proportion of patients who received prehospital TXA increased with the BATT score. There was no loss to follow-up at 30 days. A total of $2517(2.4 \%)$ patients died within $24 \mathrm{~h}$ and 8874 (8.5\%) died within 30 days. Early death with evidence of haemorrhage was reported for 1219 (1.2\%) patients.

\section{External validation}

The Table 3 shows the performance of the BATT score. The scaled Brier score was $6 \%$. The receiving operator curve, the sensitivity and specificity at different thresholds of the BATT score are shown in Supplementary files 4 and 5 . A threshold of 2 or more had a sensitivity of $99 \%$ and a negative likelihood ratio of 0.03 . The Cstatistic was $0.90 ; 95 \%$ CI $(0.89-0.91)$. The observed $(1.16 \%)$ and predicted $(1.15 \%)$ probabilities of death due to bleeding were similar $(p=0.81)$. The calibration curve 
Table $\mathbf{2}$ Characteristics of the trauma patients used to validate the BATT score

\begin{tabular}{|c|c|c|}
\hline & $N=104,862$ & Missing \\
\hline Mean age (SD) & $62(24)$ & 0 \\
\hline$<18, \mathrm{~N}(\%)$ & $5616(5)$ & - \\
\hline $18-44, N(\%)$ & $19,744(19)$ & - \\
\hline $45-64, N(\%)$ & $26,354(25)$ & - \\
\hline $65-74, \mathrm{~N}(\%)$ & $13,123(13)$ & - \\
\hline$\geq 75, \mathrm{~N}(\%)$ & $40,025(38)$ & - \\
\hline Sex female, N (\%) & $47,346(45)$ & 0 \\
\hline Penetrating injury, N (\%) & $3189(3)$ & 0 \\
\hline Circumstances, N (\%) & & 0 \\
\hline Motor vehicle crash & $19,709(19)$ & - \\
\hline Fall less than $2 \mathrm{~m}$ & $65,573(62)$ & - \\
\hline Fall more than $2 \mathrm{~m}$ & $10,604(10)$ & - \\
\hline Blast - Blow - Crush & $5266(5)$ & - \\
\hline Shooting & $234(0)$ & - \\
\hline Stabbing & $2538(2)$ & - \\
\hline Other & $1938(2)$ & - \\
\hline First systolic blood pressure, mean (SD) & $138(28)$ & $12,450(12)$ \\
\hline First systolic blood pressure < 90 mmHg, N (\%) & $3033(3)$ & \\
\hline First Glasgow coma scale, N (\%) & & $12,695(12)$ \\
\hline $14-15$ & $90,579(86)$ & - \\
\hline $9-13$ & $8566(8)$ & - \\
\hline $3-8$ & $5717(6)$ & - \\
\hline First heart rate, mean (SD) & $86(20)$ & $11,479(11)$ \\
\hline Heart rate > 120 bpm, N (\%) & $5475(5)$ & \\
\hline Time from injury to ambulance arrival $<3 \mathrm{~h}, \mathrm{~N}(\%)$ & $79,430(76)$ & $50,496(48)$ \\
\hline Time from injury to hospital admission < $3 \mathrm{~h}, \mathrm{~N}(\%)$ & $63,246(60)$ & $50,465(48)$ \\
\hline Injury Severity Score, mean (SD) & $16(9)$ & 0 \\
\hline ISS 9-15, N (\%) & $58,695(56)$ & - \\
\hline ISS 16-24, N (\%) & $24,635(23)$ & - \\
\hline ISS 25-34, N (\%) & $17,682(17)$ & - \\
\hline ISS $\geq 35, \mathrm{~N}(\%)$ & $3850(4)$ & - \\
\hline Tranexamic acid treatment & $9915(9)$ & $13,115(13)$ \\
\hline Prehospital & $5185(5)$ & - \\
\hline Hospital & $4576(4)$ & - \\
\hline Unknown & $176(0.1)$ & \\
\hline Any blood product received & $4922(5)$ & 0 \\
\hline Massive transfusion protocol activated & $2487(2)$ & - \\
\hline Blood received within $6 \mathrm{~h}$ of injury & $2277(2)$ & - \\
\hline
\end{tabular}

showed slight over-prediction in low risk patients and under-prediction in intermediate and high-risk patients (Supplementary file 6). The calibration intercept was close to zero (0.00032) with a calibration slope of 1.09 (Table 3).

\section{Clinical usefulness}

Figure 2 is a decision curve analysis showing the number of deaths due to bleeding avoided by TXA treatment by BATT score threshold. Treating all trauma patients as soon as possible at scene or in the ambulance prevented 


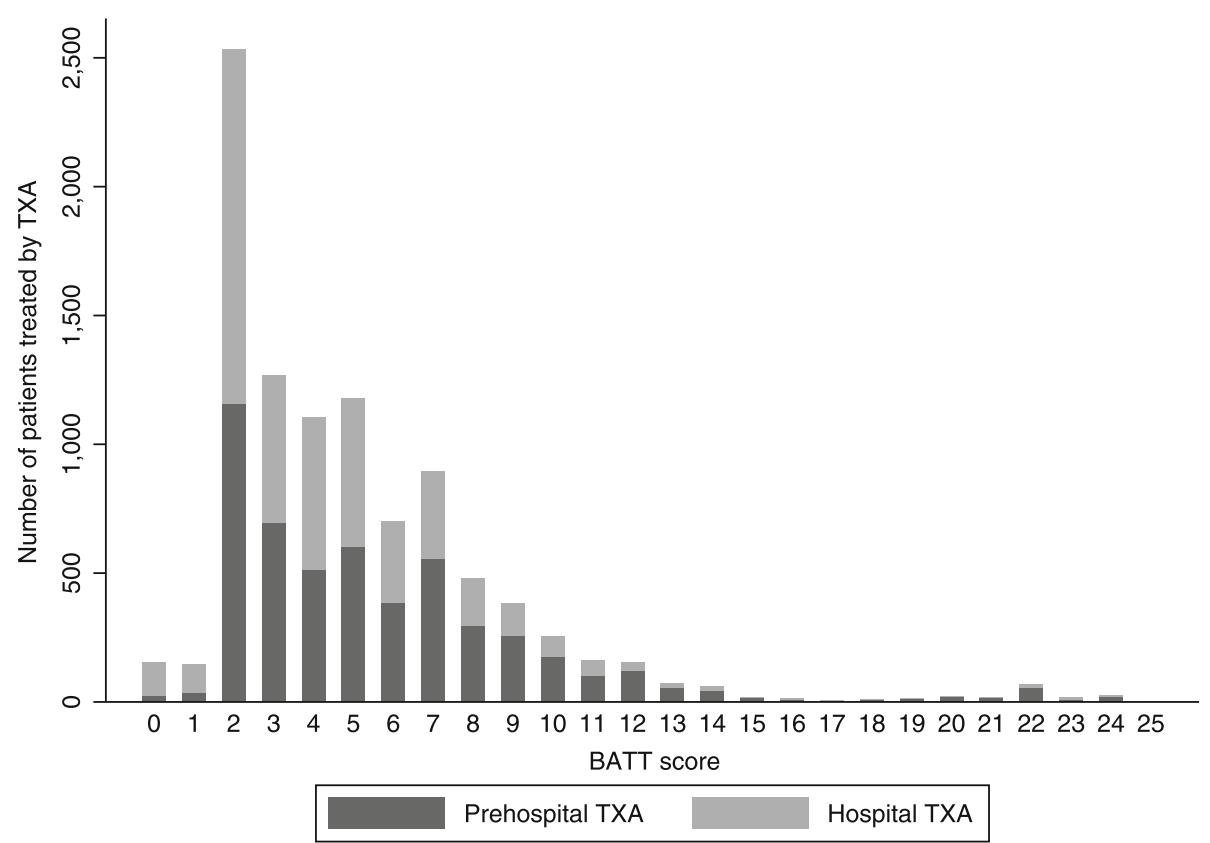

Fig. 1 Number of patients treated with tranexamic acid by BATT score in UK TARN data

more deaths than in hospital treatment. The cumulative number of deaths avoided decreased as the BATT score threshold increased. Table 4 shows the number of deaths avoided for the different scenarios and the sensitivity analysis based on observed early deaths in 2017 and 2018 in England and Wales. The sensitivity analysis confirms that prehospital treatment provides the maximum benefit with a lower number needed to treat than hospital treatment. Table 5 shows the number of deaths

Table 3 Performance of the BATT score

\begin{tabular}{|c|c|c|}
\hline & BATT score & $95 \% \mathrm{Cl}$ \\
\hline \multicolumn{3}{|l|}{ Overall performance } \\
\hline Brier score & 0.0107 & \\
\hline Scaled Brier score (\%) & 6 & \\
\hline \multicolumn{3}{|l|}{ Discrimination } \\
\hline C-statistic & 0.90 & $0.89-0.91$ \\
\hline \multicolumn{3}{|l|}{ Mean predicted death due to bleeding (\%) } \\
\hline If patient died from bleeding & 6.5 & \\
\hline If patient did not die from bleeding & 1.1 & $1.1-1.1$ \\
\hline Discrimination slope (\%) & 5.4 & $0.053-0.056$ \\
\hline \multicolumn{3}{|l|}{ Calibration } \\
\hline Observed deaths due to bleeding (\%) & 1.16 & $1.1-1.2$ \\
\hline Predicted deaths due to bleeding (\%) & 1.15 & $1.1-1.2$ \\
\hline Calibration-in-the-large (\%) & 0.01 & $0.00-0.01$ \\
\hline Ratio Predicted/Observed & 0.99 & $0.94-1.05$ \\
\hline Calibration Intercept & 0.00032 & \\
\hline Calibration slope & 1.09 & $1.07-1.11$ \\
\hline
\end{tabular}

avoided and the number needed to treat for each BATT score threshold when patients are treated as soon as possible in the prehospital setting and within $3 \mathrm{~h}$ of injury. A BATT score treatment threshold of 2 corresponds to the treatment of 61,598 patients $(59 \%$ of major trauma patients included in TARN registry with ISS $\geq 9$ ) and results in 210 deaths avoided (Table 5). A BATT score treatment threshold below 2 resulted in 6 to 14 additional deaths avoided with an additional number needed to treat for one death avoided more than 1000 patients (Table 5, Fig. 3).

\section{Discussion \\ Main findings}

In 2017 and 2018, only 9\% of trauma patients in England and Wales received TXA and only $3 \%$ received it within an hour of injury. Pre-hospital treatment of trauma patients with a BATT score of 2 or more would substantially increase the number of premature deaths that could be avoided with TXA.

\section{Strengths and limitations}

Our study has important strengths. Our prognostic score was derived using multivariable methods within a large international prospective cohort study with minimal missing data. We then validated the score in a second large cohort that was not used to derive the score [19]. We validated the BATT score in data from a large national trauma registry which includes trauma patients with a wide range of bleeding severity thus providing a heterogenous case-mix that allows accurate assessment 


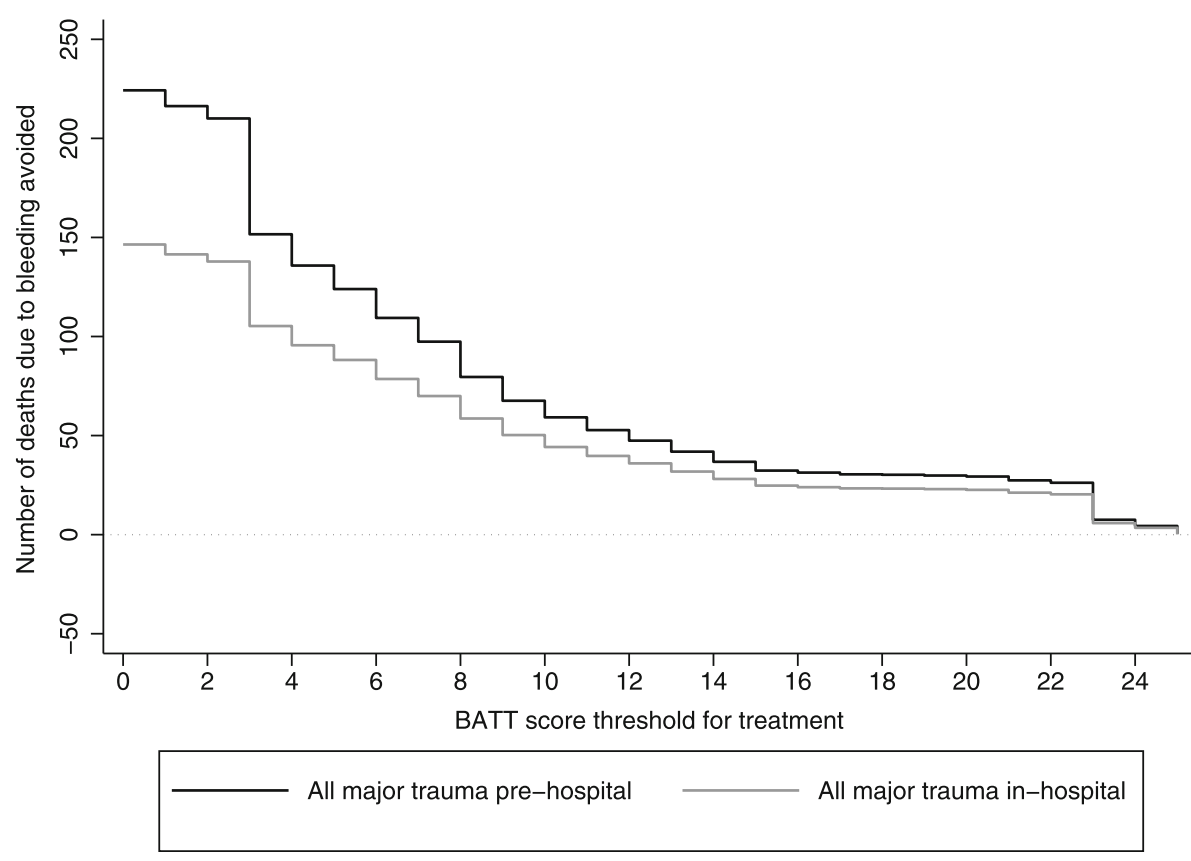

Fig. 2 Impact of tranexamic acid treatment by BATT score threshold

of discrimination [20]. The score is based on variables recorded by paramedics at the scene of the injury when the decision to treat with TXA must be made. The large number of patients in this study increases the precision of the results. There were few missing values for predictor variables and no missing outcome data. The outcome was well defined and recorded at fixed time point. These strengths help to ensure the validity of the results.

Our study also has limitations. Measurement error of predictor variables could affect discrimination and calibration. Random error could arise for all predictors (blood pressure, heart rate, Glasgow Coma scale, Respiratory rate) and lead to reduce discrimination and calibration. Systematic errors arising from the use of monitoring devices is more likely to affect calibration [21]. Because the outcome 'death due to bleeding' was not available in TARN database, we used early death as a proxy for death due to bleeding [22]. However, any outcome misclassification would be expected to decrease the C-statistic and reduce model performance [23] and

Table 4 Comparison of number of deaths due to bleeding avoided by tranexamic acid treatment

\begin{tabular}{|c|c|c|c|c|}
\hline & $\begin{array}{l}\text { Patients treated } N(\%) N= \\
104,862\end{array}$ & $\begin{array}{l}\text { Deaths avoided } \mathrm{N} \\
(95 \% \mathrm{Cl})\end{array}$ & $\begin{array}{l}\text { Deaths avoided per } 10,000 \text { patients } \\
N(95 \% \mathrm{Cl})\end{array}$ & $\begin{array}{l}\text { Number needed to treat to avoid } \\
\text { one death }\end{array}$ \\
\hline \multicolumn{5}{|c|}{ Based on predicted probabilities } \\
\hline $\begin{array}{l}\text { Current } \\
\text { strategy }^{\mathrm{a}}\end{array}$ & 9915 (11) & $55(54-57)$ & $5(5-5)$ & 180 \\
\hline $\begin{array}{l}\text { All } \\
\text { prehospital }\end{array}$ & $79,430(76)$ & $224(220-228)$ & $21(21-22)$ & 355 \\
\hline $\begin{array}{l}\text { All in } \\
\text { hospital }\end{array}$ & $63,246(60)$ & $146(144-149)$ & $14(14-14)$ & 430 \\
\hline \multicolumn{5}{|c|}{ Based on observed probabilities (sensitivity analysis) ${ }^{b}$} \\
\hline $\begin{array}{l}\text { Current } \\
\text { strategy }\end{array}$ & $9915(11)$ & $168(157-178)$ & $16(15-17)$ & 59 \\
\hline $\begin{array}{l}\text { All } \\
\text { prehospital }\end{array}$ & $79,430(76)$ & $323(305-341)$ & $31(29-33)$ & 244 \\
\hline $\begin{array}{l}\text { All in } \\
\text { hospital }\end{array}$ & $63,246(60)$ & $240(226-253)$ & $22(21-24)$ & 273 \\
\hline
\end{tabular}

NNT Number Needed to Treat

${ }^{a}$ Current strategy observed in the UK-TARN data based on clinical judgment and current guidelines in UK

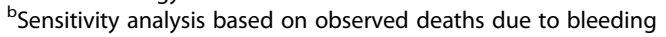


Table 5 Number of deaths due to bleeding avoided and number needed to treat with pre-hospital treatment within $3 \mathrm{~h}$ of injury according to BATT score threshold as treatment criteria

\begin{tabular}{|c|c|c|c|c|c|c|}
\hline $\begin{array}{l}\text { BATT Score } \\
\text { Threshold for } \\
\text { TXA treatment }\end{array}$ & $\begin{array}{l}\text { Total patients } \\
\text { included in } \\
\text { TARN N (\%) }\end{array}$ & $\begin{array}{l}\text { Number of patients } \\
\text { considered for } \\
\text { treatment }^{\mathrm{a}} \mathrm{N}(\%)\end{array}$ & $\begin{array}{l}\text { Number of deaths } \\
\text { avoided by BATT } \\
\text { score threshold }\end{array}$ & $\begin{array}{l}\text { Standardized } \\
\text { number of deaths } \\
\text { avoided per } 10,000\end{array}$ & $\begin{array}{l}\text { Number } \\
\text { needed to } \\
\text { treat }^{b}\end{array}$ & $\begin{array}{l}\text { Additional NNT' for } \\
\text { change of one point } \\
\text { of BATT score }\end{array}$ \\
\hline$\geq 14$ & $586(<1)$ & $534(<1)$ & 37 & 4.7 & 14 & - \\
\hline$\geq 13$ & $737(<1)$ & $671(<1)$ & 42 & 5.3 & 16 & 27 \\
\hline$\geq 12$ & $960(1)$ & $883(1)$ & 47 & 5.9 & 19 & 42 \\
\hline$\geq 11$ & $1266(1)$ & $1150(1)$ & 53 & 6.7 & 22 & 45 \\
\hline$\geq 10$ & $1727(2)$ & $1557(2)$ & 59 & 7.4 & 27 & 23 \\
\hline$\geq 9$ & $2533(2)$ & $2272(2)$ & 68 & 8.6 & 34 & 79 \\
\hline$\geq 8$ & $3859(4)$ & $3420(3)$ & 80 & 10.1 & 43 & 128 \\
\hline$\geq 7$ & $6879(7)$ & $5898(6)$ & 97 & 12.2 & 61 & 146 \\
\hline$\geq 6$ & $10,071(10)$ & $8584(8)$ & 109 & 13.7 & 78 & 224 \\
\hline$\geq 5$ & $16,032(15)$ & $13,335(13)$ & 124 & 15.6 & 108 & 317 \\
\hline$\geq 4$ & $22,946(22)$ & $18,769(18)$ & 136 & 17.1 & 138 & 452 \\
\hline$\geq 3$ & $33,483(32)$ & $27,062(26)$ & 152 & 19.1 & 179 & 518 \\
\hline$\geq 2$ & $80,071(76)$ & $61,598(59)$ & 210 & 26.4 & 293 & 595 \\
\hline$\geq 1$ & $89,948(86)$ & $68,452(65)$ & 216 & 27.2 & 316 & 1142 \\
\hline$\geq 0$ & $104,862(100)$ & $79,430(76)$ & 224 & 28.2 & 354 & 1372 \\
\hline
\end{tabular}

TXA Tranexamic acid, NNT Number needed to treat

${ }^{a}$ Number of trauma patients within $3 \mathrm{~h}$ of injury and the arrival of the first ambulance. Proportions are based on all patients included in the TARN registry with ISS $\geq 9$

${ }^{\mathrm{b}}$ Standardized number of deaths avoided per 10,000 trauma patients within $3 \mathrm{~h}$ included in the TARN registry with an ISS $\geq 9$

'Additional trauma patients needed to treat for each death avoided compared to the BATT score threshold above
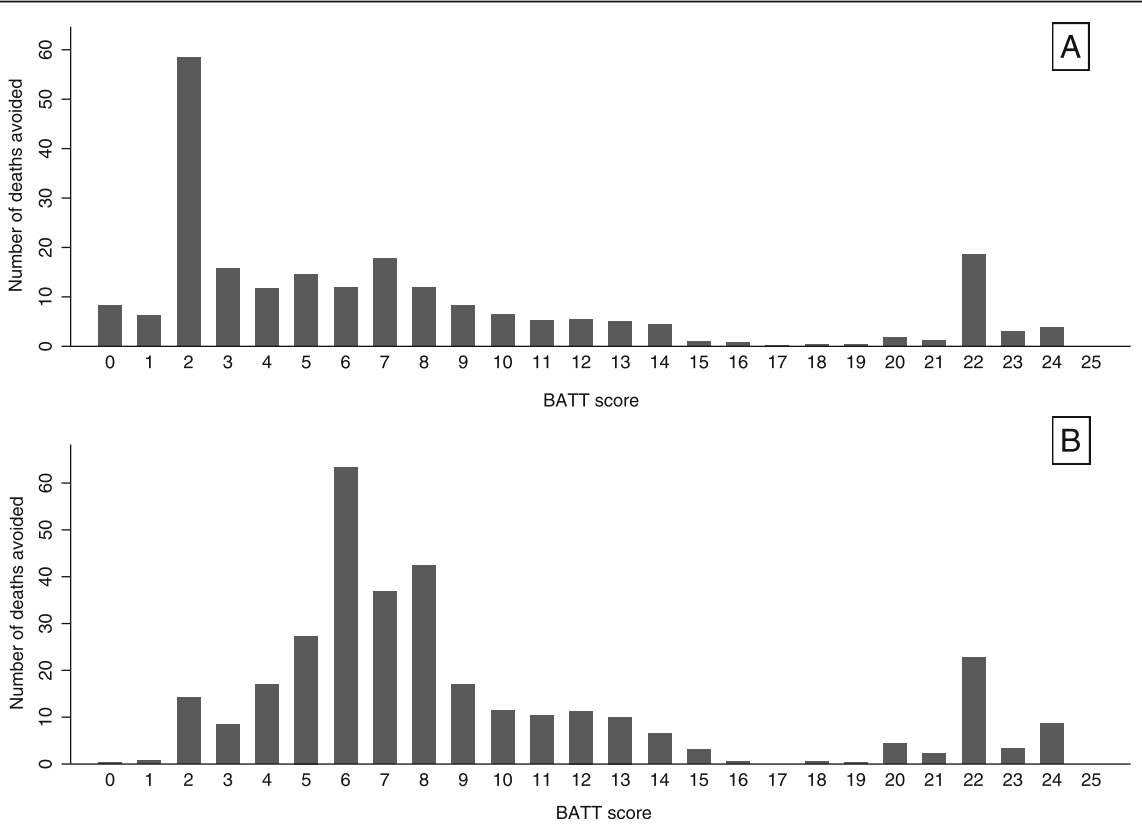

Fig. 3 Number of deaths avoided due to prehospital tranexamic acid by BATT score. a: Estimated number of deaths avoided based on predicted baseline risk. b: Estimated number of deaths avoided based on observed probabilities of death (Sensitivity analysis) 
since the C-statistic was high and model performance was excellent, misclassification is unlikely to be an important weakness. Because time from injury to ambulance arrival and hospital admission was missing for nearly half of the patients, we imputed these data. Misclassification of time to treatment could affect our estimate of the net benefit [24]. The estimates of deaths avoided are unlikely to be generalizable since they depend on the risk of death, which may vary in different settings. To model the number of deaths avoided, we used treatment effect estimates from randomised trials and so the estimates should be unconfounded. However, confounders in this observational study might affect our estimates of the absolute number of deaths avoided and so this must be considered with caution. Because we used the same method to estimate the impact of each strategy, it is unlikely that the comparison between different strategies was adversely affected by potential confounders. Furthermore, we are reassured by the result of the STAAMP trial assessing TXA in trauma patient in the prehospital setting [25]. The magnitude of the treatment effect observed in this trial is similar to that observed in the CRASH-2 trial although the estimate was more imprecise.

\section{Relation to other studies}

To the best of our knowledge, ours is the only score that predicts traumatic death due to bleeding. Existing haemorrhage scores predict massive transfusion which is an imperfect surrogate of death due to bleeding and vulnerable to survival bias (i.e. TASH score, ABC score) [26, 27].

\section{Clinical implications}

Clinical guidelines recommend TXA treatment for patients with or at risk of significant bleeding and that treatment is given as soon as possible [3]. Due to the lack of clear treatment criteria, many trauma patients are not receiving TXA or else receive it too late. A study on paramedic perceptions concerning tranexamic acid use in bleeding in trauma patients showed that lack of self-confidence, uncertainty about haemorrhage risk and the need to give TXA by slow intravenous injection (over $10 \mathrm{~min}$ ) were the main barriers to TXA administration [28]. Our data suggest that using a BATT score threshold of 2 or more would improve outcomes with a fourfold increase in bleeding deaths prevented by TXA. This clear criterion could improve prehospital administration of TXA by paramedics. Although the use of this threshold would increase the number of patients treated, TXA is safe and inexpensive and is likely to be highly cost-effective [29, 30]. Randomised trials of TXA in trauma and surgery have included over 50,000 patients and no increase in vascular occlusive events has been found [4, 17, 31-33]. Recent trials in prehospital trauma did not find any increase in vascular occlusive events associated with TXA and provide evidence for applicability of TXA treatment in the prehospital setting [25, 34].

Recent research has found that TXA is well tolerated and rapidly absorbed after intramuscular injection reaching therapeutic concentrations within 15 min in bleeding trauma patients [35]. Further research is needed to assess the cost-effectiveness of different treatment thresholds and whether use of the BATT score and intramuscular TXA administration by paramedics increases the pre-hospital administration of TXA to patients at risk of bleeding from trauma. Prospective validation of the BATT score would certainly increase its value for clinical use.

\section{Conclusion}

The BATT score is a validated tool, easy to perform at the scene of injury to identify trauma patients at risk of death from bleeding. A score of 2 or more would be an appropriate threshold for pre-hospital tranexamic acid treatment.

\section{Supplementary Information}

The online version contains supplementary material available at https://doi. org/10.1186/s13049-020-00827-5.

Additional file 1: Supplementary file 1. Abbreviated Injury Scale diagnosis associated with haemorrhage. Supplementary file 2. Formula for the Brier Score and Scaled Brier Score. Supplementary file 3. Methods to model tranexamic acid treatment effect and death due to bleeding avoided. Supplementary file 4. Receiving Operator Curve for external validation of the BATT score. Supplementary Figure $\mathbf{5}$.

Sensitivity and specificity according to BATT score for death due to bleeding. Supplementary file $\mathbf{6}$. Calibration curve for external validation of the BATT score.

\section{Acknowledgements \\ We thank TARN and all hospitals participating to the network; Professor Jonathan Benger for his support to develop the BATT score.}

Authors' contributions

FXA, IR designed the study. TC designed and monitored the data collection from which this paper was developed. FXA analysed the data. VD, TC gave feedback about the clinical use. FXA, IR wrote the first draft. FXA, TC, VD, IR contributed to write and revised the paper. The author(s) read and approved the final manuscript.

\section{Funding}

This study did not receive any fund.

Availability of data and materials

Data are available on reasonable request and with agreement from TARN.

Ethics approval and consent to participate

The TARN Registry has ethical approval TARN from the UK Health Research Authority (section 251 PIAG) for analysis of the anonymized data.

Consent for publication

Not applicable. 


\section{Competing interests}

All authors declare no support from any organisation for the submitted work; no financial relationships with any organisations that might have an interest in the submitted work in the previous 3 years; no other relationships or activities that could appear to have influenced the submitted work.

\section{Author details}

'Clinical Trials Unit, London School of Hygiene \& Tropical Medicine, London WC1E 7HT, UK. ${ }^{2}$ Department of Emergency Medicine, Lausanne University Hospital, University of Lausanne, 1011 Lausanne, Switzerland. ${ }^{3}$ Emergency Medicine, University of Leicester, Leicester, UK.

Received: 24 August 2020 Accepted: 15 December 2020 Published online: 06 January 2021

\section{References}

1. CRASH-2 trial collaborators, Shakur H, Roberts I, Bautista R, Caballero J, Coats T, et al. Effects of tranexamic acid on death, vascular occlusive events, and blood transfusion in trauma patients with significant haemorrhage (CRASH2): a randomised, placebo-controlled trial. Lancet. 2010;376:23-32.

2. Ker K, Edwards P, Perel P, Shakur H, Roberts I. Effect of tranexamic acid on surgical bleeding: systematic review and cumulative meta-analysis. BMJ. 2012;344:e3054.

3. Spahn DR, Bouillon B, Cerny V, Duranteau J, Filipescu D, Hunt BJ, et al. The European guideline on management of major bleeding and coagulopathy following trauma: fifth edition. Crit Care. 2019;23:98.

4. Gayet-Ageron A, Prieto-Merino D, Ker K, Shakur H, Ageron F-X, Roberts I, et al. Effect of treatment delay on the effectiveness and safety of antifibrinolytics in acute severe haemorrhage: a meta-analysis of individual patient-level data from 40138 bleeding patients. Lancet. 2018;391:125-32.

5. Ageron F-X, Gayet-Ageron A, Steyerberg E, Bouzat P, Roberts I. Prognostic model for traumatic death due to bleeding: cross-sectional international study. BMJ Open. 2019;9:e026823.

6. Ageron F-X, Gayet-Ageron A, Ker K, Coats TJ, Shakur-Still H, Roberts I, et al. Effect of tranexamic acid by baseline risk of death in acute bleeding patients: a meta-analysis of individual patient-level data from 28333 patients. Br J Anaesth. 2020;124:676-83.

7. van Laarhoven JJEM, Lansink KWW, van Heijl M, Lichtveld RA, Leenen LPH. Accuracy of the field triage protocol in selecting severely injured patients after high energy trauma. Injury. 2014;45:869-73.

8. Lecky F, Woodford M, Yates D. Trends in trauma care in England and Wales 1989-97. Lancet. 2000;355:1771-5.

9. Demetriades D, Murray J, Charalambides K, Alo K, Velmahos G, Rhee P, et al. Trauma fatalities: time and location of hospital deaths. J Am Coll Surg. 2004; 198:20-6.

10. Søreide K, Krüger AJ, Vårdal AL, Ellingsen CL, Søreide E, Lossius HM. Epidemiology and contemporary patterns of trauma deaths: changing place, similar pace, older face. World J Surg. 2007:31:2092-103.

11. Pfeifer R, Teuben M, Andruszkow H, Barkatali BM, Pape H-C. Mortality Patterns in Patients with Multiple Trauma: A Systematic Review of Autopsy Studies. PLoS One. 2016;11. Available from: https://www.ncbi.nlm.nih.gov/ pmc/articles/PMC4752312/ [cited 2020 Nov 27].

12. Lefering R, Paffrath T, Bouamra O, Coats TJ, Woodford M, Jenks T, et al. Epidemiology of in-hospital trauma deaths. Eur J Trauma Emerg Surg. 2012; 38:3-9.

13. Steyerberg EW, Vickers AJ, Cook NR, Gerds T, Gonen M, Obuchowski N, et al. Assessing the performance of prediction models: a framework for some traditional and novel measures. Epidemiology. 2010;21:128-38.

14. Peng P, Coyle A. Likelihood ratios for the emergency physician. Acad Emerg Med. 2018;25:958-65.

15. Hanley JA, McNeil BJ. The meaning and use of the area under a receiver operating characteristic (ROC) curve. Radiology. 1982;143:29-36.

16. Stevens RJ, Poppe KK. Validation of clinical prediction models: what does the "calibration slope" really measure? J Clin Epidemiol. 2020;1 18:93-9.

17. Franchini M, Mengoli C, Marietta M, Marano G, Vaglio S, Pupella S, et al. Safety of intravenous tranexamic acid in patients undergoing majororthopaedic surgery: a meta-analysis of randomised controlled trials. Blood Transfus. 2018;16:36-43.

18. Vickers AJ, Van Calster B, Steyerberg EW. Net benefit approaches to the evaluation of prediction models, molecular markers, and diagnostic tests.
BMJ. 2016;352 Available from: https://www.ncbi.nlm.nih.gov/pmc/articles/ PMC4724785/ [cited 2019 Apr 2]

19. Steyerberg EW, Harrell FE. Prediction models need appropriate internal, internal-external, and external validation. J Clin Epidemiol. 2016:69:245-7.

20. Damen JAAG, Debray TPA, Pajouheshnia R, Reitsma JB, Scholten RJPM, Moons KGM, et al. Empirical evidence of the impact of study characteristics on the performance of prediction models: a meta-epidemiological study. BMJ Open. 2019;9:e026160.

21. Rosella LC, Corey P, Stukel TA, Mustard C, Hux J, Manuel DG. The influence of measurement error on calibration, discrimination, and overall estimation of a risk prediction model. Popul Health Metrics. 2012;10:20.

22. Brenner A, Arribas M, Cuzick J, Jairath V, Stanworth S, Ker K, et al. Outcome measures in clinical trials of treatments for acute severe haemorrhage. Trials. 2018;19 Available from: https://www.ncbi.nlm.nih.gov/pmc/articles/PMC616 $7881 /$ [cited 2019 Apr 2].

23. Jurek AM, Greenland S, Maldonado G, Church TR. Proper interpretation of non-differential misclassification effects: expectations vs observations. Int J Epidemiol. 2005;34:680-7.

24. van Doorn S, Brakenhoff TB, Moons KGM, Rutten FH, Hoes AW, Groenwold $\mathrm{RHH}$, et al. The effects of misclassification in routine healthcare databases on the accuracy of prognostic prediction models: a case study of the CHA2DS2-VASC score in atrial fibrillation. Diagn Progn Res. 2017;1 Available from: https://www.ncbi.n/m.nih.gov/pmc/articles/PMC6460749/ [cited 2020 Apr 17].

25. Guyette FX, Brown JB, Zenati MS, Early-Young BJ, Adams PW, Eastridge BJ, et al. Tranexamic Acid During Prehospital Transport in Patients at Risk for Hemorrhage After Injury: A Double-blind, Placebo-Controlled, Randomized Clinical Trial. JAMA Surg. 2020; Available from: https://jamanetwork.com/ journals/jamasurgery/fullarticle/2771225 [cited 2020 Oct 22].

26. Nunez TC, Voskresensky IV, Dossett LA, Shinall R, Dutton WD, Cotton BA. Early prediction of massive transfusion in trauma: simple as $A B C$ (assessment of blood consumption)? J Trauma. 2009;66:346-52.

27. Yücel $N$, Lefering $R$, Maegele $M$, Vorweg $M$, Tjardes T, Ruchholtz $S$, et al. Trauma associated severe hemorrhage (TASH)-score: probability of mass transfusion as surrogate for life threatening hemorrhage after multiple trauma. J Trauma. 2006;60:1228-36 discussion 1236-1237.

28. Nicholson H. Paramedic perceptions of bleeding in trauma and the use of tranexamic acid. 2020. Available from: https://uwe.cloud.panopto.eu/ Panopto/Pages/Viewer.aspx?id=c673a0d2-e8e3-4cbf-8634-abf800b35828 [cited 2020 Aug 19].

29. Meybohm P, Straub N, Füllenbach C, Judd L, Kleinerüschkamp A, Taeuber I, et al. Health economics of patient blood management: a cost-benefit analysis based on a meta-analysis. Vox Sang. 2020;115:182-8.

30. Guerriero C, Cairns J, Perel P, Shakur H, Roberts I. CRASH 2 trial collaborators. Cost-effectiveness analysis of administering tranexamic acid to bleeding trauma patients using evidence from the CRASH-2 trial. PLoS One. 2011;6: e18987.

31. Myles PS, Smith JA, Forbes A, Silbert B, Jayarajah M, Painter T, et al. Tranexamic acid in patients undergoing coronary-artery surgery. N Engl J Med. 2017;376:136-48.

32. Sentilhes $L$, Winer $N$, Azria E, Sénat M-V, Le Ray C, Vardon D, et al. Tranexamic acid for the prevention of blood loss after vaginal delivery. $\mathrm{N}$ Engl J Med. 2018;379:731-42

33. Sprigg N, Flaherty K, Appleton JP, Salman RA-S, Bereczki D, Beridze M, et al. Tranexamic acid for hyperacute primary IntraCerebral Haemorrhage $(\mathrm{TICH}-$ 2): an international randomised, placebo-controlled, phase 3 superiority trial. Lancet. 2018;391:2107-15.

34. Rowell SE, Meier EN, McKnight B, Kannas D, May S, Sheehan K, et al. Effect of out-of-hospital Tranexamic acid vs placebo on 6-month functional neurologic outcomes in patients with moderate or severe traumatic brain injury. JAMA. 2020;324:961-74.

35. Grassin-Delyle S, Shakur-Still H, Picetti R, Frimley L, Jarman H, Davenport R, et al. Pharmacokinetics of intramuscular tranexamic acid in bleeding trauma patients: a clinical trial. Br J Anaesth. 2020; Accepted for publication.

\section{Publisher's Note}

Springer Nature remains neutral with regard to jurisdictional claims in published maps and institutional affiliations. 